\title{
Development of Pure Culture Biofilms of P. putida on Solid Supports
}

\author{
Gina S. Shreve, ${ }^{1,2}$ Ronald H. Olsen, ${ }^{3}$ and Timothy M. Vogel ${ }^{1,4 *}$ \\ ${ }^{\prime}$ Environmental and Water Resources Engineering, ${ }^{2}$ Department of Chemical \\ Engineering, ${ }^{3}$ Department of Microbiology and Immunology, ${ }^{4}$ Department of \\ Civil Engineering, The University of Michigan, Ann Arbor, Michigan 48109-2125
}

Received January 26, 1990/Accepted August 9, 1990

Pseudomonas putida biofilms were developed on and biofilm accumulation rate data were obtained for the following two classes of support materials: charged surfaces and noncharged hydrophobic and hydrophilic surfaces. The effects of surface roughness and porosity on the rate of microbial attachment were also examined.

Materials bearing a net positive or negative surface charge supported the greatest biofilm accumulation and the highest biofilm accumulation rate. Uncharged hydrophobic materials achieved the next greatest biofilm accumulation, averaging approximately $50 \%$ of the total biomass which was accumulated on the charged surface materials after 16 days. Uncharged hydrophilic materials supported very little biofilm development. In general, biofilm accumulation increased with decreasing surface roughness. The effect of pore size on biofilm accumulation was not conclusive.

The biofilm accumulation kinetics showed an exponential accumulation rate for the charged surfaces and an approximately linear accumulation rate for the hydrophobic materials. This difference in accumulation kinetics is consistent with proposed differences in the physicochemical mechanism governing attachment to these two types of surface materials.

\section{INTRODUCTION}

Pseudomonas species are currently being considered for numerous applications such as protein production,' bioreactor processes for hazardous waste degradation, ${ }^{2}$ and for in situ bioremediation schemes. ${ }^{3}$ Biofilm systems are expected to have a large and expanded role in these applications. ${ }^{3}$ The use of Pseudomonas species requires an understanding of their physical properties and behavior under application conditions such as those in which cells are growing attached to solid supports.

While attachment of Pseudomonas species has been demonstrated on numerous support materials, ${ }^{4-7}$ a comparative quantitation of Pseudomonas biofilm development on such supports has not been performed. Gram-negative microorganisms, such as Pseudomonas, have been reported to bind well to positively charged anion exchange resins under conditions of physiological (neutral) $\mathrm{pH}^{5,8,9}$ They have also been reported to bind well to hydrophobic materials such as polystyrene, ${ }^{6}$ polyethylene, ${ }^{7}$ and polytetrafluoroethylene (PFTE or teflon). ${ }^{10}$ In addition, adhesion of gram-negative micro-

\footnotetext{
* To whom all correspondence should be addressed.
}

organisms to other materials such as cation exchange resins $^{11}$ and soils ${ }^{12}$ has been examined. However, no systematic effort has been made to compare the attachment of a microbial species on these types of support materials under identical culture conditions.

In principle, the attachment of microorganisms to surfaces is influenced by long-range, short-range, and hydrodynamic forces. Current models of the attachment process include long-range forces which act to bring the organism into close proximity to a surface and shortrange forces which serve to hold the organism at the surface..$^{13}$ Long-range forces include electrical charge interactions, which may be attractive or repulsive, and the dispersion contribution to the van der Waals forces. ${ }^{13}$ Short-range forces include dipole-dipole (Keesom) interactions, dipole-induced dipole (Debye) interactions, ion-dipole interactions, and hydrogen bonding. ${ }^{13}$ Hydrodynamic forces are involved in bacterial transport to the surface as well as the production of shear stresses which contribute to the removal of bacteria from the surface. ${ }^{14}$ The experiments described in this paper were conducted in a constant hydrodynamic environment. They attempted to compare the kinetics of microbial accumulation on different surfaces where initial attachment rates are controlled by either long-range or shortrange forces.

The surface materials tested may be grouped into two classes possessing physical surface properties which are expected to influence microbial attachment to the surface: those possessing a surface charge and those possessing no net surface charge. The first class of materials - those possessing charged surfaces-would be expected to exhibit accumulation kinetics consistent with attachment controlled by long-range charge interactions. The uncharged materials would be expected to exhibit attachment kinetics controlled by short-range forces mediated by the hydrophobic or hydrophilic character of the support material. Surfaces such as the charged resins, which possess both long-range and short-range properties, are expected to exhibit more rapid accumulation kinetics than surfaces possessing only short-range properties. Therefore, if the attachment process can be viewed as a two step process governed by long-range and hydrodynamic forces which hasten the rate of transport of the microorganism to 
the surface and short-range forces which serve to hold the bacteria there, the overall attachment process should be more rapid for surfaces possessing long-range force properties if the rate-limiting step for the attachment process is the movement of the microorganism to the surface.

Understanding which physical forces control the attachment kinetics will be useful for choosing the best biofilm support material for a particular process application. An understanding of the biofilm accumulation kinetics of Pseudomonas species on various classes of support materials may also be useful for predicting their survival in field applications with differing soil environments and in oligotrophic environments where attachment probably provides a survival advantage. ${ }^{15}$

This study examined the ability of several biofilm support materials to promote the attachment of the gram-negative bacterium, Pseudomonas putida, under controlled culture conditions. This study also provides preliminary evidence that materials which interact with microorganisms through long-range intermolecular forces exhibit different microbial attachment kinetics than materials interacting with suspended microorganisms solely through short-range intermolecular forces.

\section{MATERIALS AND METHODS}

\section{Microorganism}

Pseudomonas putida strain ppO301 (pRO103) contains the plasmid pRO103 encoding the tfd ABCD genes which are constitutively expressed to produce gene products which degrade 2,4-dichlorophenoxyacetic acid $(2,4-\mathrm{D})$ to chloromaleylacetic acid. ${ }^{16}$

\section{Media and Innoculation Procedures}

P. putida ppO301 (pRO103) was maintained on tryptone nitrate broth plates ${ }^{17}$ with $50 \mu \mathrm{g} / \mathrm{mL}$ tetracycline. One hundred milliliters of a microbial culture, which had been grown up overnight to an optical density of approximately 1.2 OD units at $425 \mathrm{~nm}$ was innoculated into $1400 \mathrm{~mL} \mathrm{RBC}$ reactors containing MMO mineral medium $^{18}$ with either $0.3 \%$ or $0.05 \%$ casamino acids as the sole carbon source. The culture was grown in batch mode until an optical density of approximately 0.4 at $425 \mathrm{~nm}$ wavelength was reached. The rotating cylinder containing the biofilm support materials was then added to the reactor. Continuous flow operation was then begun at a dilution rate of $0.0514 \mathrm{~h}^{-1}$.

\section{Biofilm Support Materials}

Twenty-one different commercially available support materials were used to examine biofilm growth (Table I). Polyethylene and polystyrene support materials were wet sanded with increasingly coarse grades (Nos. 600, 400 , and 220) of sandpaper to examine the effect of surface roughness on biofilm formation.

\section{Equipment}

The biofilm development experiments were performed in continuously fed rotating biological contactors

Table I. Support materials used for attachment of Pseudomonas putida in rotating biological contactor.

\begin{tabular}{lll}
\hline Support Material & \multicolumn{1}{c}{ Description } & \multicolumn{1}{c}{ Source } \\
\hline $\begin{array}{l}\text { Charged: } \\
\mathrm{SiO}_{2} \text { TLC plate }\end{array}$ & $(-)$ charge & \\
$\mathrm{Al}_{2} \mathrm{O}_{3}$ TLC plate & $(+)$ charge & Anspec, Ann Arbor, MI \\
$\mathrm{DEAE}$ TLC plate & $(+)$ basic anion exchange & Anspec, Ann Arbor, MI \\
Biotrace NT & $(-)$ nitrocellulose & Whatman, Hillsboro, OR \\
Biotrace RP & $(+)$ charge. Derivatized nylon & Gelman, Ann Arbor, MI \\
AP20 & $(+)$ borosilicate microfiber & Gelman, Ann Arbor, MI \\
AW19 & $(+)$ cellulose ester microfiber & Millipore, Bedford, MA \\
Hydrophobic: & & Millipore, Bedford, MA \\
Polystyrene & Bacterial grade petri dish (UR) & \\
Polystyrene & No. 600 surface roughed & Becton Dickenson, \\
Polystyrene & No. 400 surface roughed & Lincoln Park, NJ \\
Polystyrene & No. 220 surface roughed & Lincoln Park, NJ \\
Polystyrene & High density commercial (UR) & Lincoln Park, NJ \\
Polystyrene & No. 600 surface roughed & Envirex, Waukesha, WI \\
Polystyrene & No. 400 surface roughed & Envirex, Waukesha, WI \\
Polystyrene & No. 220 surface roughed & Envirex, Waukesha, WI \\
Fluoropore & PTFE 1- $\mu$ m pore & Envirex, Waukesha, WI \\
Fluoropore & PTFE 3- $\mu$ m pore & Millipore, Bedford, MA \\
Mitex & PTFE 5- $\mu$ m pore & Millipore, Bedford, MA \\
Immobilon P & polyvinylidene difluoride & Millipore, Bedford, MA \\
Hydrophilic: & & Millipore, Bedford, MA \\
Versapore & acrylic copolymer & \\
Duropore & modified polyvinylidene difluoride & Millipore, Bedford, MA \\
\hline & &
\end{tabular}


(RBCs) with working volumes of $1.4 \mathrm{~L}$. The $\mathrm{RBC}$ system is shown schematically in Figure 1. The RBC design parameters are given in Table II. The design parameters were chosen to simulate commercial RBCs and other currently used research systems. ${ }^{19}$

Two identical RBCs were built and were operated containing either biofilm support material or stainlesssteel disks, which were shown not to support significant biofilm development over the course of these experiments. The liquid medium was maintained at a level which covered approximately $60 \%$ of the disks' surface. The disk rotation rate was $30 \mathrm{rpm}$.

Each disk was constructed with six removable $1-\mathrm{cm}^{2}$ sections. Sections were prepared by cutting the disk materials with a hot nickel-chrome wire. Each disk, with its removable sections, was then bound by spray adhesive to a stainless-steel disk and placed in the reactor.

\section{Biofilm Experiments}

Biofilm accumulation was quantified using protein concentration as a surrogate parameter. The Lowry method was used to determine the protein concentration on each removable disk section. ${ }^{20}$ Sections were removed from the reactor at various times throughout the course of the biofilm experiment using a sterile scalpel and forceps. The sections were rinsed with gentle agitation for approximately $30 \mathrm{~s}$ in sterile medium and then subjected to biofilm quantitation. Each $1-\mathrm{cm}^{2}$ section was

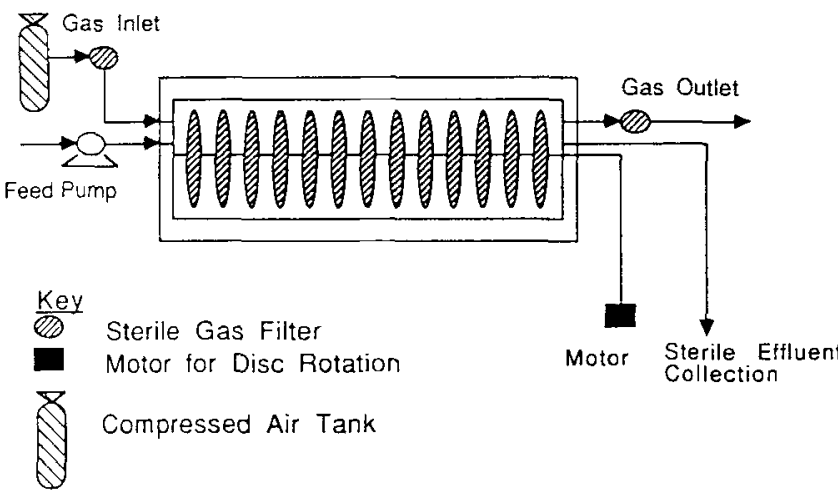

Figure 1. Schematic of rotating biological contactor used for all bioreactor experiments.

Table II. Dimensions and operating parameters for the rotating biological contactors (RBCs).

\begin{tabular}{lc}
\hline Internal volume & $3635 \mathrm{~cm}^{3}$ \\
Liquid volume & $1.4 \mathrm{~L}$ \\
Gas volume & $200-1600 \mathrm{~cm}^{3}$ \\
Number of disks & $1-36$ \\
Disk diameter & $11.43 \mathrm{~cm}$ \\
Disk thickness & $0.85 \mathrm{~mm}$ \\
Support spacing & $2-20 \mathrm{~mm}$ adjustable \\
Total support surface area & $205-7390 \mathrm{~cm}^{2}$ \\
Percent submergence & $50-100 \%$ adjustable \\
Drive speed range & $6-120 \mathrm{rpm}^{2}$ adjustable \\
Surface-to-volume ratio & $0.0732-5.28 \mathrm{~cm}^{-1}$ \\
\hline
\end{tabular}

then resuspended in $1 \mathrm{~mL}$ sterile water. Two milliliters of the Lowry reagent containing $2 \%$ sodium carbonate in $0.1 \mathrm{~N}$ sodium hydroxide, resulting in a solution with a $\mathrm{pH}$ greater than 11.0, was then added to lyse the cells and denature the released proteins. Protein assays then proceeded as per the previously published Lowry method.$^{20}$ Results of protein assays on blank disk materials, which were immersed in media and then similarly rinsed and assayed, were either zero or less than $20 \mu \mathrm{g}$ protein $/ \mathrm{cm}^{2}$. These protein values were then subtracted from their respective support material experimental values before the data was further analyzed. Initial assays in triplicate of the disk sections gave protein concentration values which varied less than $2-3 \%$ between replicates. Sections at varying radial distances from the center of the disk were also tested to determine if increasing hydrodynamic shear, although small, affected biofilm accumulation with increased distance from the disk center. Biofilm concentrations were determined to be unaffected by the radial distance of the disk section. Measurements of biofilm accumulation are expressed in either micrograms of cellular protein or number of cells $/ \mathrm{cm}^{2}$ surface area of the solid support. Protein assays performed on standardized numbers of cells yielded an average protein value of $3.8 \times 10^{-6} \mu \mathrm{g}$ protein/cell.

Residence time distribution analysis using a pulse tracer method resulted in an inverse Pechlet number near 20. This analysis indicated that the reactor system approximated a well-mixed continuously stirred tank reactor with no axial concentration profile. For the biofilm accumulation studies, the reactors were operated at steady state in which the dilution rate was controlled to maintain an approximately constant optical density culture with a constant cell concentration.

\section{RESULTS}

Pseudomonas putida biofilm accumulation on the twenty-one materials listed in Table I was first measured with $0.05 \%$ casamino acids as the sole carbon and energy source. Two classes of support materials supported significant biofilm accumulation of $P$. putida ppO301 (pRO103). These were the charged materials and the hydrophobic materials, polyethylene in particular. Hydrophilic uncharged materials did not exhibit significant accumulation. Biofilm accumulation on those materials supporting biofilm development was measured again in a separate experiment with $0.3 \%$ casamino acid concentration.

Of the two classes of support materials which were reexamined, charged and hydrophobic surfaces, the charged surface materials (Fig. 2) once again showed much higher biomass accumulation rates and total biofilm accumulation than the uncharged hydrophobic materials (Fig. 3).

Biofilm accumulation rates for the 21 support materials tested in the first experiment are summarized in Table III. Those for the support materials included in 


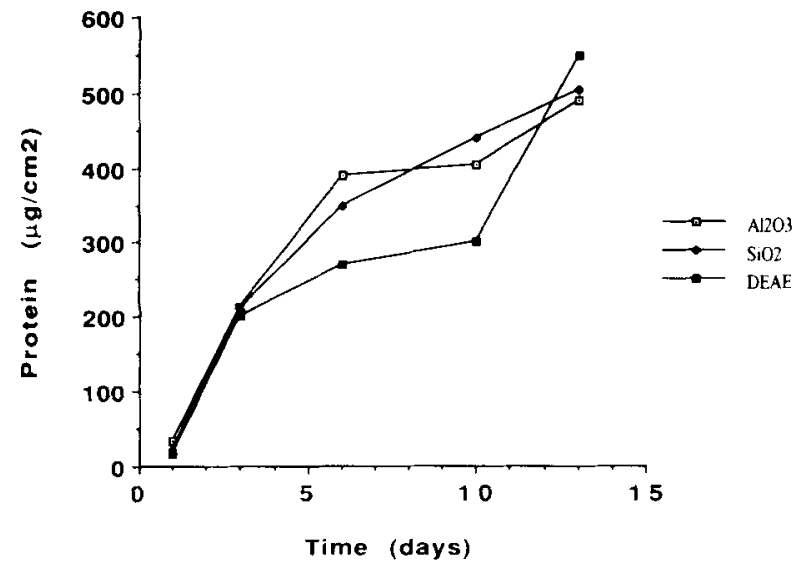

Figure 2. Biofilm accumulation kinetics on charged supports when the bioreactor was fed $0.05 \%$ casamino acids (as measured by protein accumulation). The support materials are: $(-\odot-) ; \mathrm{Al}_{2} \mathrm{O}_{3}$, (-) $\mathrm{SiO}_{2}$, and (- - - ); DEAE.

the second experiment are summarized in Table IV. The initial rate data presented in Tables III and IV are the result of linear regression analysis of the data for the first four days of each bioreactor run. The biofilm accumulation kinetics for the various materials were similar between the two runs. The doubling time for batch cultures of $P$. putida ppO301 (pRO103) on $0.3 \%$ casamino acids was $60 \mathrm{~min}$. The doubling times of the attached cells grown on $0.3 \%$ casamino acids, as measured by protein accumulation, would have been between three and seven days, depending on the support material had the observed biofilm accumulation been attributable to growth of attached cells. This indicates that the biofilm accumulation kinetics were governed by attachment rather than biofilm growth since a difference this large in doubling time, if this were interpreted to represent doubling time, would not be expected to occur upon attachment.

Several reports ${ }^{21,22}$ have suggested that for a monolayer, nearly all of the progeny from binary cell fission detach, and that the rate of detachment of irreversibly attached monolayer cells is negligible. ${ }^{23}$ Therefore, the rate of cellular accumulation on the surface would be dominated by the attachment rate of the microorganisms as indicated by the accumulation data obtained. The total amount of biofilm accumulated after 16 days was roughly proportional to the primary carbon source concentration. The optical densities $\left(\mathrm{OD}_{425}\right)$ of the resulting cultures were approximately 0.76 and 2.8 for the bioreactor fed $0.05 \%$ and $0.3 \%$ casamino acids, respectively. Attached cell concentrations for biofilms grown in the presence of $0.3 \%$ casamino acids were approximately five- to sixfold higher than for those grown on $0.05 \%$ casamino acids. The fact that the accumulation kinetics appear to be directly related to cell concentration in the reactor also indicates that attachment, and not growth in the biofilm, was being measured, since attachment kinetics have been previously demonstrated to be dependent on cell concentration. ${ }^{24}$

The pore size of the support material appeared to influence microbial attachment to the teflon membranes. The $1-\mu \mathrm{m}$ pore Fluoropore Teflon membrane supported greater biofilm accumulation than the $3-\mu \mathrm{m}$ pore Fluoropore membrane. Both the 1- and 3- $\mu \mathrm{m}$ Teflon membranes supported greater attachment than the 5- $\mu \mathrm{m}$ pore Mitex Teflon membrane (Table III). This trend, however, was not apparent in the experiment with cells grown on $0.3 \%$ casamino acids. A large amount of variability in the data made it impossible to verify the effect of substrate pore size on biofilm accumulation.

Surface roughness of the support material also seemed to influence biofilm accumulation for the culture grown on $0.05 \%$ casamino acids. Decreasing surface roughness of the support promoted increased biofilm accumulation with the unroughened surface showing the least accumulation and the Nos. 220,400 , and 600 roughened plastic surfaces showing increasing accumulation for cells grown on $0.05 \%$ casamino acids on the polyethylene supports. This trend was not as clear for the cells grown on $0.05 \%$ casamino acids on the polystyrene supports or for the cells grown on $0.3 \%$ casamino acids.

The charged supports accumulated the most biofilm over the 16-day period of the experiments indicating

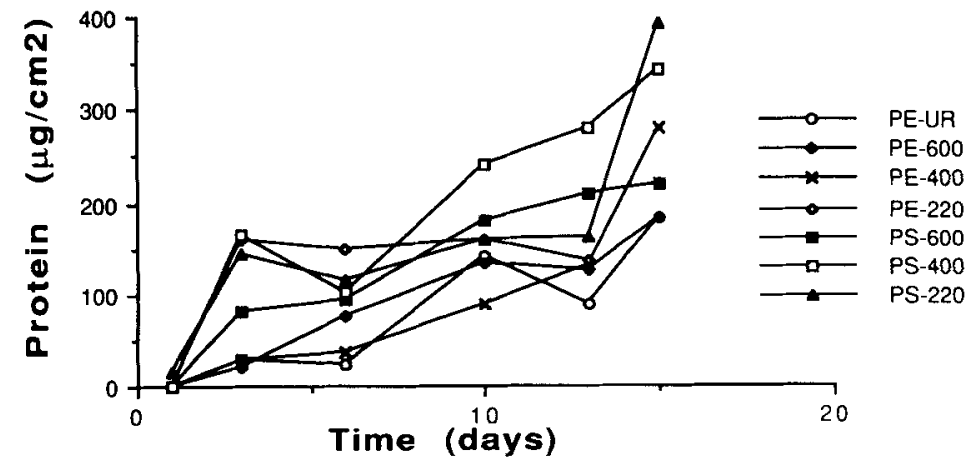

Figure 3. Biofilm accumulation kinetics on hydrophobic supports when the bioreactor was fed $0.3 \%$ casamino acids (as measured by protein accumulation). The support materials are: $(-\infty))$ PE-UR, $(-\rightarrow)$ PE-600, $(-\leftarrow)$

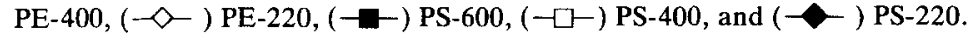


Table III. Biofilm accumulation kinetics on disks of rotating biological contactor fed with $0.05 \%$ casamino acids.

\begin{tabular}{|c|c|c|c|c|}
\hline \multirow{2}{*}{$\begin{array}{l}\text { Support material } \\
\text { Charged: }\end{array}$} & \multicolumn{2}{|c|}{$\begin{array}{c}\text { Initial } \\
\text { accumulation } \\
\text { rate } \\
\left(\mu \mathrm{g} / \mathrm{cm}^{2} / \text { day }\right)\end{array}$} & \multicolumn{2}{|c|}{$\begin{array}{l}\text { Maximum } \\
\text { biofilm } \\
\text { accumulation } \\
\left(\mu \mathrm{g} / \mathrm{cm}^{2}\right)\end{array}$} \\
\hline & \multicolumn{2}{|c|}{$\left(\text { cells } / \mathrm{cm}^{2} / \text { day } \times 10^{-6}\right)^{\mathrm{a}}$} & \multicolumn{2}{|c|}{$\left(\text { cells } / \mathrm{cm}^{2} \times 10^{-6}\right)^{\mathrm{a}}$} \\
\hline $\mathrm{SiO}_{2}$ & 8.75 & 2.303 & 100 & 26.32 \\
\hline $\mathrm{Al}_{2} \mathrm{O}_{3}$ & 5.0 & 1.32 & 80 & 21.05 \\
\hline DEAE & 10.0 & 2.63 & 70 & 18.42 \\
\hline Biotrace NT & 2.5 & 0.658 & $30^{\mathrm{a}}$ & 7.89 \\
\hline Biotrace RP & 1.75 & 0.461 & $20^{a}$ & 5.26 \\
\hline AP20 & 17.5 & 4.61 & 220 & 57.89 \\
\hline AW19 & $\begin{array}{c}2.5 \\
\text { Average }=6.9\end{array}$ & $\begin{array}{c}0.658 \\
\text { Average }=1.82\end{array}$ & $\begin{array}{c}90 \\
\text { Average }=87.0\end{array}$ & $\begin{array}{c}23.68 \\
\text { Average }=22.89\end{array}$ \\
\hline \multicolumn{5}{|l|}{ Hydrophobic: } \\
\hline Polystyrene UR & 10.0 & 2.63 & $25^{\mathrm{b}}$ & 6.58 \\
\hline Polystyrene 600 & 4.5 & 3.82 & 40 & 10.53 \\
\hline Polystyrene 400 & 1.25 & 0.329 & $10^{\mathrm{b}}$ & 2.63 \\
\hline Polystyrene 220 & 2.5 & 0.658 & 10 & 2.63 \\
\hline Polyethylene UR & 3.75 & 0.987 & $10^{b}$ & 2.63 \\
\hline Polyethylene 600 & 5.0 & 1.32 & 80 & 21.05 \\
\hline Polyethylene 400 & 1.25 & 0.329 & 35 & 9.21 \\
\hline Polyethylene 220 & 6.25 & 1.645 & 20 & 5.26 \\
\hline Immobilon $\mathbf{P}$ & 3.75 & 0.987 & 20 & 5.26 \\
\hline Fluoropore $1 \mu \mathrm{m}$ & 5.0 & 1.32 & 80 & 21.05 \\
\hline Fluoropore $3 \mu \mathrm{m}$ & 1.25 & 0.329 & 30 & 7.89 \\
\hline Mitex & $\begin{array}{c}5.0 \\
\text { Average }=\end{array}$ & $\begin{array}{c}1.32 \\
\text { Average }=108\end{array}$ & $20^{b}$ & $\begin{array}{l}5.26 \\
\text { e }=8.34\end{array}$ \\
\hline \multicolumn{5}{|l|}{ Hydrophilic: } \\
\hline Versapore & 0.0 & 0.0 & 15 & 3.95 \\
\hline Duropore & $\begin{array}{c}0.0 \\
\text { Average }=0.0\end{array}$ & $\begin{array}{c}0.0 \\
\text { Average }=0.0\end{array}$ & $\begin{array}{c}10 \\
\text { Average }=12.5\end{array}$ & $\begin{array}{c}2.63 \\
\text { Average }=3.29\end{array}$ \\
\hline
\end{tabular}

${ }^{\mathrm{a}} \mathrm{This}$ is $3.8 \times 10^{-6} \mu \mathrm{g}$ protein/cell conversion applied,

${ }^{b}$ Indicates an approximate steady state biofilm value.

Table IV. Biofilm accumulation kinetics on disks of rotating biological contactor fed with $0.3 \%$ casamino acids.

\begin{tabular}{|c|c|c|c|c|}
\hline \multirow{2}{*}{$\frac{\text { Support material }}{\text { Charged: }}$} & \multicolumn{2}{|c|}{$\begin{array}{c}\text { Initial } \\
\text { accumulation } \\
\text { rate } \\
\left(\mu \mathrm{g} / \mathrm{cm}^{2} / \text { day }\right)\end{array}$} & \multicolumn{2}{|c|}{$\begin{array}{l}\text { Maximum } \\
\text { biofilm } \\
\text { accumulation } \\
\left(\mu \mathrm{g} / \mathrm{cm}^{2}\right)\end{array}$} \\
\hline & \multicolumn{2}{|c|}{$\left(\text { cells } / \mathrm{cm}^{2} / \text { day } \times 10^{-6}\right)^{\mathrm{a}}$} & \multicolumn{2}{|c|}{$\left(\text { cells } / \mathrm{cm}^{2} \times 10^{-6}\right)^{\mathrm{a}}$} \\
\hline $\mathrm{SiO}_{2}$ & 62.7 & 16.5 & 505 & 132.89 \\
\hline $\mathrm{Al}_{2} \mathrm{O}_{3}$ & 59.8 & 15.74 & 490 & 128.95 \\
\hline DEAE & $\begin{array}{c}61.0 \\
\text { Average }=61.2\end{array}$ & $\begin{array}{c}16.05 \\
\text { Average }=16.11\end{array}$ & $\begin{array}{c}515 \\
\text { Average }=503.3\end{array}$ & $\begin{array}{c}135.53 \\
\text { Average }=132.45\end{array}$ \\
\hline \multicolumn{5}{|l|}{ Hydrophobic: } \\
\hline Polystyrene 600 & 26.7 & 7.03 & $220^{\mathrm{b}}$ & 57.89 \\
\hline Polystyrene 400 & 55.0 & 14.47 & 343 & 90.26 \\
\hline Polystyrene 220 & 42.2 & 11.11 & $393^{b}$ & 103.42 \\
\hline Polyethylene UR & 9.5 & 2.5 & $183^{b}$ & 48.16 \\
\hline Polyethylene 600 & 6.7 & 1.76 & 183 & 48.16 \\
\hline Polyethylene 400 & 9.2 & 2.42 & 280 & 73.68 \\
\hline Polyethylene 220 & $\begin{array}{c}53.3 \\
\text { Average }=28.9\end{array}$ & $\begin{array}{c}14.03 \\
\text { Average }=7.61\end{array}$ & $\begin{array}{c}135^{\mathrm{b}} \\
\text { Average }=259\end{array}$ & $\begin{array}{c}35.53 \\
\text { Average }=68.16\end{array}$ \\
\hline
\end{tabular}

${ }^{\mathrm{a}}$ This is $3.8 \times 10^{-6} \mu \mathrm{g}$ protein/cell conversion applied.

${ }^{b}$ Indicates an approximate steady state biofilm value. 
that for P. putida ppO301 (pRO103) charged materials are preferred for attachment. Both the initial attachment rates and the maximum biofilm accumulation obtained, presented in Tables III and IV, were approximately twofold greater for the charged supports than for the uncharged supports. However, since a steady-state biofilm was not achieved, a comparison between steadystate biofilm loading on the charged supports and the hydrophobic supports is not yet possible.

\section{DISCUSSION}

The charged surfaces supported the greatest total biofilm development. The DEAE anion exchange resin and the silicon and aluminum oxide resins accumulated the most biofilm in this study. The final cell loading achieved is consistent with previously published reports of the capacity of positively charged surfaces for cells. ${ }^{11}$ Calculations based on a cell size of $0.5 \times 1 \mu \mathrm{m}$ cell size, and using values of protein content measured for a standard number of suspended ppO301 (pRO103) cells, indicated biofilms with maximum densities in the range of $1 \times 10^{7}$ to $1 \times 10^{8}$ cells $/ \mathrm{cm}^{2}$. These values fall into the range of reported cell densities obtained for Pseudomonas monolayers. ${ }^{4}$

Silicon oxide is a weakly acidic material and aluminum oxide is a weakly basic material. This implies that the net surface charge of the silicon oxide would be negative and that of the aluminum oxide would be positive under the culture conditions employed. The DEAE anion exchange resin possesses a positive charge under the experimental conditions used. Hydrogen bonding, in addition to charge interactions, may be involved in adhesion of $P$. putida to these supports particularly for the silicon and aluminum oxide supports. The Biotrace RP and the Biotrace NT were the exceptions among the charged surfaces, because they did not show substantial biofilm accumulation. This may be due to a lower charge density than the other charged materials tested.

The glass microfiber samples were not considered for reevaluation in the second bioreactor run because of their porosity and high absorptive capacity and interference by the microfiber material in the protein assay. Although this high absorptive capacity caused the glass microfiber disks to achieve the highest cell loading, the interaction between the cells and the support was probably not mediated by surface absorption onto the glass microfibers but rather through absorption and entrapment by the spongelike microfiber membranes.

The hydrophobic surfaces tested supported greater attachment than the hydrophilic surfaces which is consistent with earlier studies by Fletcher and Loeb. ${ }^{7}$ They reported that a marine Pseudomonas species exhibited greater surface attachment to hydrophobic surfaces than to hydrophilic surfaces, however, attachment kinetics were not examined.

Decreasing surface roughness appeared to contribute to biofilm development in the first bioreactor run al- though the second bioreactor run data does not show such a clear trend. Decreasing surface roughness results in a lower friction factor for the surface and decreased frictional resistance to fluid flow. ${ }^{25}$ It has been shown that for completely rough surfaces the laminar sublayer near the surface is completely disrupted. ${ }^{25}$ Since the maximum biofilm coverage attained was a monolayer, there should be little change in the frictional resistance, or smoothing, of the surface due to microbial attachment throughout the experiments. Powell and Slater found that increasing fluid velocity, or increased frictional resistance, resulted in a decreased rate of attachment and a lower number of attached cells. ${ }^{26}$ They concluded that this was due to a decreased amount of time spent by the cell in the vicinity of the surface resulting in a reduced ability to bond irreversibly to the surface through exopolymer bridging. ${ }^{26}$ Other groups, however, have observed increased colonization of rougher substratum. ${ }^{27}$ It has recently been pointed out that little conclusive evidence is currently available to quantify the effect of substratum surface roughness on biofilm formation ${ }^{27,28}$ and further examination is required to establish a clear trend.

The accumulation rate data for the materials which supported microbial attachment were fit by either a least-squares linear regression or a second- or thirdorder exponential curve-fitting procedure. In general, accumulation kinetics for the charged resins exhibited exponential biofilm accumulation rates whereas most of the hydrophobic materials were described best by linear accumulation rates. Attachment of the microorganisms to the charged supports would be expected to occur predominantly via electrostatic forces, whereas London-van-der-Waals forces and interfacial tension would predominate for absorption to the hydrophobic support materials.

Materials capable of exerting long-range electrostatic forces, which serve to bring the microorganisms into close proximity to the surface, would be expected to demonstrate more rapid microbial attachment than materials lacking such physical properties. Uncharged materials which lack these long-range net attractive forces would, therefore, be expected to show slower microbial attachment rates. Thus, the observed difference in biofilm accumulation kinetics for these two classes of support materials is likely to result from these two different mechanisms of attraction of the microorganisms to the charged or hydrophobic support materials.

For each bioreactor run, the average initial biofilm accumulation rates, presented in Tables III and IV, of the charged materials were substantially higher than those of the hydrophobic materials. This indicates that charge-charge interactions may play a significant role in controlling the rate of microbial attachment to solid surfaces. This conclusion is also supported by an earlier study by Dexter et al. ${ }^{10}$ which found that glass supported a much higher attachment rate than hydrophobic materials such as polystyrene and polytetrafluoro- 
ethylene, and that after $15 \mathrm{~h}$ attachment rates remained exponential on the glass surface while the polystyrene and polytetrafluoroethylene attachment rates were approximately linear for marine biofouling studies in harbor seawater.

Although the charged supports also accumulated, on average, approximately twice the total biomass of the hydrophobic supports, the lack of attainment of steady state biofilm loading for each material during the bioreactor runs make the comparison of final steady state loading capacities difficult.

The significantly lower rates of attachment and total biofilm accumulation on the Biotrace NT nitrocellulose and Biotrace RP nylon charged membranes indicates that either the charge density of these supports is not on the same order of magnitude as the other charged materials or that another property such as the surface roughness of the DEAE and aluminum and silicon oxide TLC plate supports is primarily responsible for the higher rate of attachment to the TLC plate supports. Further study is also needed to more accurately determine the influence of surface roughness and porosity on the rate of microbial attachment to support materials.

This work was done in the Departments of Chemical and Civil Engineering and the Department of Microbiology and Immunology, The University of Michigan (Ann Arbor, MI) with financial support from the Office of the Vice President for Research, University of Michigan, and the U.S. Environmental Protection Agency, Office of Exploratory Research, R816127-01. The authors express their gratitude to Dr. Larry Montgomery for his helpful review of the manuscript.

\section{References}

1. A. Persson, E. Osterberg, and M. Dostalek, Appl. Microbiol. Biotechnol., 29, 1 (1988).

2. H. M. Ehrhardt and H. J. Rehm, Appl. Microbiol. Biotechnol., 21, 32 (1985)

3. M. D. Lee, J. M. Thomas, R. C. Borden, P. B. Bedient, C. H. Ward, and J.T. Wilson, CRC Crit. Rev. Environ. Control, 18, 29 (1989).
4. G. Molin, I. Nilsson, and L. Stenson-Holst, Eur. J. Appl. Microbiol. Biotechnol., 15, 218 (1982).

5. S. D. Hogg, Ph.D. thesis, University of Salford, 1976.

6. M. Fletcher, Can. J. Microbiol., 23, 1 (1977).

7. M. Fletcher and G.I. Loeb, Appl. Environ. Microbiol., 37, 67 (1979).

8. R. Hattori, T. Hattori, and C. Furusaka, J. Gen. Appl. Microbiol., 18, 271 (1972).

9. T. Hattori and C. Furusaka, J. Biochem., 50, 312 (1961).

10. S. C. Dexter, J. D. Sullivan, Jr., J. Williams III, and S.W. Watson, Appl. Microbiol., 30, 298 (1975).

11. J. M. Wood, in Microbial Adhesion to Surfaces, R. C.W. Berkeley, J. M. Lynch, J. Melling, P. R. Rutter, and B. Vincent, Eds. (Halsted, New York, 1980), p. 163.

12. R. G. Burns, in Adhesion of Microorganisms to Surfaces, D. C. Ellwood, J. Melling, and P. Rutter, Eds. (Academic, New York, 1979), p. 109.

13. P. R. Rutter and B. Vincent, in Microbial Adhesion and Aggregation. Life Sciences Research Report 31, K. C. Marshall, Ed. (Springer-Verlag, Dahlem Konferenzen, 1984), p. 21.

14. J. Bryers and W. Characklis, Biotechnol. Bioeng., 24, 2451 (1982).

15. H. Heukelekian and A. Heller, J. Bacteriol., 40, 547, (1940).

16. A. R. Harker, R. H. Olsen, and R. J. Seidler, J. Bacteriol., 171, 314 (1989).

17. R. H. Olsen and P. Shipley, J. Bacteriol., 113, 772 (1973).

18. R. N. Stanier, N. J. Palleroni, and M. Doudoroff, J. Gen. Microbiol., 43, 149 (1966).

19. M. Laquidara, F. C. Blanc, and J. C. O'Shaughnessy, J. Water Pollut. Control Fed., 58, 107 (1986).

20. O. H. Lowry, N. J. Rosebrough, A. L. Farr, and R. J. Randall, J. Biol. Chem., 193, 265 (1951).

21. P. Gilbert, Appl. Environ. Microbiol., 55, 1308, (1989).

22. D. E. Caldwell, Ann. Acad. Sci., 506, 274 (1987).

23. J. D. Bryers, Biotechnol. Progress, 3, 57 (1987).

24. W. G. Characklis, in Biofilms, W. G. Characklis and K. C. Marshall, Eds., (Wiley, New York, 1990), p. 333.

25. H. Schlichting, in Boundary-Layer Theory, 6th ed. (McGrawHill, New York, 1968), p. 583.

26. M. S. Powell and N. K. H. Slater, Biotechnol. Bioeng., 25, 891 (1983).

27. W. G. Characklis, in Biofilms, W. G. Characklis and K. C. Marshall, Eds., (Wiley, New York, 1990), p. 219.

28. W. G. Characklis, in Biofilms, W. G. Characklis and K. C. Marshall, Eds., (Wiley, New York, 1990), p. 219. 